\title{
ABO blood group is a predictor of survival in patients with laryngeal cancer
}

\author{
Ting Jin ${ }^{1,2+}$, Pei-Jing $\mathrm{Li}^{3+}{ }^{\text {, Xiao-Zhong Chen }}{ }^{1,2^{*}}$ and Wei-Han $\mathrm{Hu}^{3^{*}}$
}

\begin{abstract}
Background: Whether the $\mathrm{ABO}$ blood group is associated with the survival of patients with laryngeal cancer remains unknown. The purpose of this study was to investigate the association between the ABO blood group and clinicopathologic characteristics of patients with laryngeal cancer and assess whether the ABO blood group was associated with prognosis.

Methods: We analyzed the records of 1260 patients with laryngeal cancer who underwent curative treatment at Sun Yat-sen University Cancer Center between January 1993 and December 2009. The Chi-square test was used to assess the relationship between the ABO blood group and clinicopathologic characteristics. The Kaplan-Meier method was used to estimate 3-, 5-, and 10-year overall survival (OS) rates. The Cox proportional hazards model was used in univariate and multivariate analyses of OS.

Results: No significant association was found between the $\mathrm{ABO}$ blood group and clinicopathologic characteristics except for primary tumor site. The median OS for patients with blood groups $A, B, A B$, and $O$ were 87.0, 80.0, 90.0, and 72.5 months, respectively. The 3-, 5-, and 10-year OS rates were $82.4 \%, 76.0 \%$, and $67.5 \%$ for patients with blood group A; $77.4 \%, 69.8 \%$, and $58.4 \%$ for patients with blood group $B ; 82.2 \%, 73.1 \%$, and $65.6 \%$ for patients with blood group $A B$; and $71.7 \%, 66.4 \%$, and $55.5 \%$ for patients with blood group $O$, respectively. Univariate and multivariate analyses showed that the $\mathrm{ABO}$ blood group had significant effects on prognosis in patients with laryngeal cancer.
\end{abstract}

Conclusions: The ABO blood group is associated with survival in patients with laryngeal cancer. Patients with blood group $O$ had significantly shorter OS than patients with other $\mathrm{ABO}$ blood groups.

Keywords: The ABO blood group, Laryngeal cancer, Prognosis, Survival

\section{Background}

In the United States, it is estimated that approximately 53,640 new cases of oral cavity, pharyngeal, and laryngeal cancers were diagnosed in 2013. During the same period, an estimated 11,520 deaths from head and neck cancers occurred [1]. Approximately $20 \%$ of head and neck tumors originate in the larynx [1]. Laryngeal cancer can be largely prevented by controlling behavioral risk

\footnotetext{
*Correspondence: chenxiaozhongfy@163.com; huwh@sysucc.org.cn

${ }^{\dagger}$ Ting Jin and Pei-Jing Li contributed equally to this work

${ }^{2}$ Department of Radiation Oncology, Zhejiang Cancer Hospital, 38 Guang

Ji Road, Hangzhou 310022, Zhejiang, P. R. China

${ }^{3}$ State Key Laboratory of Oncology in South China, Department

of Radiation Oncology, Collaborative Innovation Center of Cancer

Medicine, Sun Yat-sen University Cancer Center, No. 651 Dongfeng Road

East, Guangzhou 510060, Guangdong, P. R. China

Full list of author information is available at the end of the article
}

factors, such as alcohol consumption and cigarette smoking. Human papillomavirus infection was also found to be significantly associated with the risk of laryngeal cancer [2]. Importantly, some patients without strong risk factors present with particularly aggressive laryngeal carcinoma. Such cases mandate the investigation of other possible predisposing factors, such as the $\mathrm{ABO}$ blood group [3].

Several previous studies, which, taken together, included a relatively small number of patients, examined the relationship between the $\mathrm{ABO}$ blood group and the incidence of laryngeal cancer. In 1992, in a study of people living in southern Poland, Konieczna et al. [4] found that the blood group A2B was present significantly more frequently in 153 patients with epiglottic cancer compared with 22,422 healthy individuals; however, 
the difference was not significant with respect to 3- and 5 -year survival rates. In 1995, in another study of people living in Poland, Pyd et al. [5] reported that the blood group A2 was present significantly more frequently in a group of patients with glottic cancer compared with supraglottic and subglottic cancer and that the blood group A1B was present significantly more frequently in a group of patients with hypopharyngeal cancer compared with laryngeal caner. Conversely, in 2000, Nowinska et al. [6] retrospectively studied yet another population living in southern Poland and found that differences among distinct $\mathrm{ABO}$ blood groups were not significant between 205 laryngeal cancer patients and 5168 healthy individuals. Few studies have examined the effect of the $A B O$ blood group on the survival of patients with laryngeal cancer. Adam et al. [3] reported no association between the $\mathrm{ABO}$ blood group and 5 year survival and mortality in 143 laryngeal cancer patients.

Whether the $\mathrm{ABO}$ blood group is associated with the survival of patients with laryngeal cancer remains unknown. Therefore, we retrospectively studied a consecutive cohort of patients in China who presented with locoregional laryngeal cancer and underwent curative treatment. The purpose of this study was to elucidate the association between the $\mathrm{ABO}$ blood group and the clinicopathologic characteristics of patients with laryngeal cancer and determine whether a specific $\mathrm{ABO}$ blood group is an independent predictor of prognosis.

\section{Methods}

\section{Ethics, consent, and permissions}

This study was approved by the Human Ethics Approval Committee at Sun Yat-sen University Cancer Center (registration number: B2011-06-15); requirement to obtain informed consent was waived.

\section{Patients}

We reviewed the records of patients treated at Sun Yatsen University Cancer Center between January 1993 and December 2009 and found 1477 patients with primary squamous cell carcinoma of the larynx. The patient selection criteria were as follows: (1) each patient had complete clinicopathologic data, including age, sex, stage, smoking index, alcohol consumption, histologic differentiation, the $\mathrm{ABO}$ blood group, and treatment status; (2) diseases were restaged according to the 2002 Union for International Cancer Control (UICC) cancer staging system, and no patient had distant metastasis at the time of initial staging; and (3) patients were initially treated with curative intent by one or a combination of surgery, radiation therapy, and chemotherapy. The $\mathrm{ABO}$ blood group $(\mathrm{A}, \mathrm{B}, \mathrm{O}$, or $\mathrm{AB}$ ) was determined using mouse-derived monoclonal antibodies (Ortho Bioclones Anti-A, B, and
O; Ortho Diagnostic Systems Inc., Raritan, NJ, USA). After cessation of treatment, each patient was followed up every 3 months at the clinic or by telephone contact for an interview. The last follow-up was December 31, 2013.

\section{Treatment}

Surgical methods included total laryngectomy, partial laryngectomy, and chordectomy for primary tumors. In the surgical treatment of the neck, modified radical neck dissection (MRND) and selective neck dissection (SND) were used. Cisplatin-based regimen was used for neoadjuvant chemotherapy, adjuvant chemotherapy, and concurrent chemoradiotherapy. Radiotherapy was delivered employing ${ }^{60} \mathrm{Co}$ units or 6 -MV linear accelerator. Total radiation dose in the area of clinical target volume ranged from 50 to 82 Gy (median, 60 Gy).

\section{Statistical analyses}

Overall survival (OS) was calculated from the date of diagnosis to the date of death or the last follow-up. The relationship between the $\mathrm{ABO}$ blood group and clinicopathologic variables was assessed by the Chi-square test. For univariate analysis, OS was estimated using the Kaplan-Meier method, and the statistical significance of differences between curves was tested using the logrank test. To determine independent prognostic factors, variables found to have a significant association with OS $(P<0.05)$ on univariate analyses were included in the multivariate models. $P$ values less than 0.05 were considered statistically significant. All statistical analyses were performed using the Statistical Package for the Social Sciences software (SPSS version 21.0; SPSS Inc., Chicago, IL, USA).

\section{Results}

\section{Overall study population}

Baseline clinicopathologic characteristics of the whole study population are listed in Table 1 . In total, 1260 patients were identified for our study; of these, 1226 were men, and 34 were women. For the whole cohort of patients, the median age at diagnosis was 61 years (range, 22-93 years). A total of 747 patients had UICC stage III disease, and 513 had UICC stage III-IV disease. Eight hundred eighty-five patients had glottic cancer, 331 had supraglottic cancer, and 44 had subglottic cancer. Additionally, 808 patients had never consumed alcohol, whereas 452 patients had. Three hundred forty-seven patients (27.5\%) had blood group A, 332 had blood group B (26.4\%), 101 had blood group AB (8.0\%), and 480 had blood group $\mathrm{O}(38.1 \%)$. No significant association was found between the ABO blood group and sex, age, smoking index, alcohol consumption, tumor differentiation, $\mathrm{T}$ category, N category, and UICC TNM stage (Table 1). 
Table 1 Baseline characteristics of 1260 laryngeal cancer patients divided by different ABO blood groups

\begin{tabular}{|c|c|c|c|c|c|c|c|}
\hline \multirow[t]{2}{*}{ Characteristic } & \multirow[t]{2}{*}{ Total } & \multicolumn{4}{|c|}{ ABO blood group [cases (\%)] } & \multirow[t]{2}{*}{$x^{2}$} & \multirow[t]{2}{*}{$P$} \\
\hline & & A $(n=347)$ & $\mathrm{B}(n=332)$ & $\mathrm{AB}(n=101)$ & $O(n=480)$ & & \\
\hline Sex & & & & & & 1.576 & 0.665 \\
\hline Men & 1226 & $338(27.6)$ & $320(26.1)$ & $99(8.1)$ & $469(38.2)$ & & \\
\hline Women & 34 & $9(26.5)$ & $12(35.3)$ & $2(5.9)$ & $11(32.3)$ & & \\
\hline Age (years) ${ }^{\mathrm{a}}$ & & & & & & 2.122 & 0.547 \\
\hline$\leq 61$ & 661 & $176(26.6)$ & $168(25.4)$ & $53(8.0)$ & $264(40.0)$ & & \\
\hline$>61$ & 599 & $171(28.5)$ & $164(27.4)$ & $48(8.0)$ & $216(36.1)$ & & \\
\hline Smoking index ${ }^{b}$ & & & & & & 4.010 & 0.260 \\
\hline$\leq 600$ & 659 & $191(29.0)$ & $178(27.0)$ & $45(6.8)$ & $245(37.2)$ & & \\
\hline$>600$ & 601 & $156(26.0)$ & $154(25.6)$ & $56(9.3)$ & $235(39.1)$ & & \\
\hline Alcohol consumption & & & & & & 4.899 & 0.179 \\
\hline No & 808 & $219(27.1)$ & $226(28.0)$ & $69(8.5)$ & $294(36.4)$ & & \\
\hline Yes & 452 & $128(28.3)$ & $106(23.5)$ & $32(7.1)$ & $186(41.1)$ & & \\
\hline Tumor differentiation & & & & & & 3.452 & 0.750 \\
\hline Well & 600 & $170(28.4)$ & $149(24.8)$ & $54(9.0)$ & $227(37.8)$ & & \\
\hline Moderate & 481 & $132(27.4)$ & $134(27.9)$ & $32(6.7)$ & $183(38.0)$ & & \\
\hline Poor & 179 & $45(25.1)$ & $49(27.4)$ & $15(8.4)$ & 70 (39.1) & & \\
\hline Primary site & & & & & & 16.755 & 0.010 \\
\hline Glottic & 885 & 244 (27.6) & $242(27.3)$ & $79(8.9)$ & $320(36.2)$ & & \\
\hline Supraglottic & 331 & $83(25.1)$ & $82(24.8)$ & $22(6.6)$ & $144(43.5)$ & & \\
\hline Subglottic & 44 & $20(45.5)$ & $8(18.2)$ & $0(0)$ & $16(36.3)$ & & \\
\hline T category & & & & & & 7.212 & 0.615 \\
\hline $\mathrm{T} 1$ & 434 & $119(27.4)$ & $123(28.4)$ & $31(7.1)$ & $161(37.1)$ & & \\
\hline $\mathrm{T} 2$ & 382 & $115(30.1)$ & 94 (24.6) & $31(8.1)$ & $142(37.2)$ & & \\
\hline T3 & 244 & $58(23.8)$ & 65 (26.6) & $26(10.7)$ & 95 (38.9) & & \\
\hline $\mathrm{T} 4$ & 200 & $55(27.5)$ & $50(25.0)$ & $13(6.5)$ & $82(41.0)$ & & \\
\hline N category & & & & & & 2.319 & 0.509 \\
\hline No & 1021 & $289(28.3)$ & $269(26.3)$ & $83(8.1)$ & $380(37.2)$ & & \\
\hline $\mathrm{N}+$ & 239 & $58(24.3)$ & 63 (26.4) & $18(7.5)$ & $100(41.8)$ & & \\
\hline UICC stage & & & & & & 9.077 & 0.430 \\
\hline I & 421 & $118(28.0)$ & $118(28.0)$ & $29(6.9)$ & $156(37.1)$ & & \\
\hline$\|$ & 326 & $101(31.0)$ & 77 (23.6) & $27(8.3)$ & $121(37.1)$ & & \\
\hline III & 242 & $54(22.3)$ & $66(27.3)$ & $26(10.7)$ & 96 (39.7) & & \\
\hline IV & 271 & $74(27.3)$ & $71(26.2)$ & $19(7.0)$ & $107(39.5)$ & & \\
\hline
\end{tabular}

UICC Union for International Cancer Control

a Patients were divided into two groups according to the median age

b Smoking index was defined as the number of cigarettes smoked per day $\times$ the total smoking duration (years)

Of the 1260 patients identified, 795 underwent radical resection alone, 68 received definitive radiation alone, 14 received definitive concurrent chemoradiotherapy, 298 underwent surgery plus postoperative radiotherapy, 23 underwent surgery plus adjuvant chemotherapy, 11 underwent surgery plus adjuvant concurrent chemoradiotherapy, 7 received radiotherapy before surgery, 4 received neoadjuvant chemotherapy plus surgery, 24 received neoadjuvant chemotherapy plus definitive concurrent chemoradiotherapy, 1 received concurrent chemoradiotherapy before surgery, 5 underwent surgery plus postoperative radiotherapy and adjuvant chemotherapy, 6 received neoadjuvant chemotherapy plus surgery and postoperative radiotherapy, 1 received neoadjuvant chemotherapy plus surgery and adjuvant chemotherapy, 2 received neoadjuvant chemotherapy plus surgery and adjuvant concurrent chemoradiotherapy, and 1 received neoadjuvant chemotherapy plus concurrent chemoradiotherapy and surgery. 


\section{Survival analyses by the $A B O$ blood group}

For the entire patient group, the median OS was 80 months; the 3-, 5-, and 10-year OS rates were 77.5\%, $70.5 \%$, and $60.4 \%$, respectively. The 3-, 5-, and 10 -year OS rates were $82.4 \%, 76.0 \%$, and $67.5 \%$ for patients with blood group A; 77.4\%, 69.8\%, and 58.4\% for patients with blood group B; $82.2 \%, 73.1 \%$, and $65.6 \%$ for patients with blood group AB; and 71.7\%, 66.4\%, and $55.5 \%$ for patients with blood group $\mathrm{O}$, respectively. The median OS for patients with blood groups $\mathrm{A}, \mathrm{B}, \mathrm{AB}$, and $\mathrm{O}$ was $87.0,80.0,90.0$, and 72.5 months, respectively. We found a significant difference in OS between different $\mathrm{ABO}$ blood groups $(P=0.009$; Fig. 1). Furthermore, for the entire cohort, we analyzed the association of the ABO blood group with OS rates. For patients with laryngeal cancer, univariate analyses indicated a significant association between OS rates and sex, age, smoking index, alcohol consumption, tumor differentiation, the $\mathrm{ABO}$ blood group, primary tumor site, $\mathrm{T}$ category, $\mathrm{N}$ category, and UICC TNM stage (Table 2).

Multivariate analysis showed that age, alcohol consumption, tumor differentiation, the $\mathrm{ABO}$ blood group, $\mathrm{T}$ category, and $\mathrm{N}$ category were independent prognostic factors (Table 3).

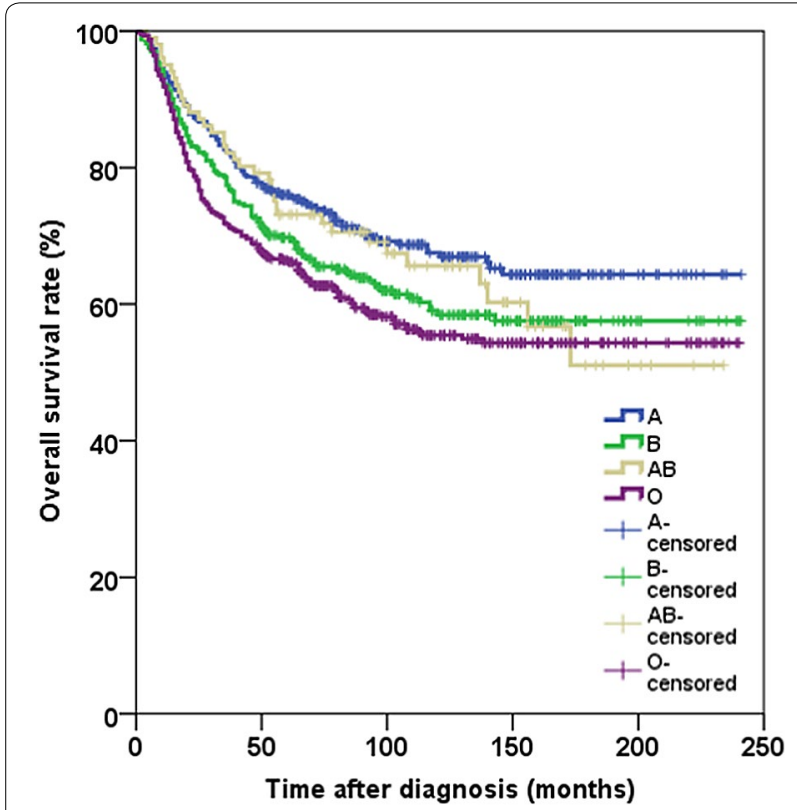

Fig. 1 Overall survival curves for 1260 laryngeal cancer patients stratified by the ABO blood group. The 3-, 5-, and 10-year OS rates were $82.4 \%, 76.0 \%$, and $67.5 \%$ for patients with blood group $A ; 77.4 \%$, $69.8 \%$, and $58.4 \%$ for patients with blood group $B ; 82.2 \%, 73.1 \%$, and $65.6 \%$ for patients with blood group $A B$; and $71.7 \%, 66.4 \%$, and $55.5 \%$ for patients with blood group $\mathrm{O}$, respectively $(P=0.009)$
Table 2 Univariate prognostic analysis for overall survival (OS) rates of 1260 patients with laryngeal cancer

\begin{tabular}{|c|c|c|c|c|c|}
\hline \multirow[t]{2}{*}{ Variable } & \multirow{2}{*}{$\begin{array}{l}\text { No. of } \\
\text { patients }\end{array}$} & \multicolumn{2}{|c|}{ OS rate (\%) } & \multirow[t]{2}{*}{$x^{2}$} & \multirow[t]{2}{*}{$P$} \\
\hline & & 5-year & 10-year & & \\
\hline Sex & & & & 6.079 & 0.014 \\
\hline Men & 1226 & 70.0 & 59.7 & & \\
\hline Women & 34 & 85.3 & 85.3 & & \\
\hline Age (years) ${ }^{a}$ & & & & 35.892 & $<0.001$ \\
\hline$\leq 61$ & 661 & 76.0 & 68.7 & & \\
\hline$>61$ & 599 & 64.4 & 51.5 & & \\
\hline Smoking index ${ }^{b}$ & & & & 8.322 & 0.004 \\
\hline$\leq 600$ & 659 & 73.2 & 64.1 & & \\
\hline$>600$ & 601 & 67.4 & 56.2 & & \\
\hline $\begin{array}{l}\text { Alcohol con- } \\
\text { sumption }\end{array}$ & & & & 4.933 & 0.026 \\
\hline No & 808 & 72.3 & 62.5 & & \\
\hline Yes & 452 & 67.2 & 56.6 & & \\
\hline Differentiation & & & & 27.775 & $<0.001$ \\
\hline Well & 600 & 76.8 & 65.7 & & \\
\hline Moderate & 481 & 68.5 & 58.4 & & \\
\hline Poor & 179 & 54.6 & 48.1 & & \\
\hline Primary site & & & & 31.102 & $<0.001$ \\
\hline Glottic & 885 & 74.8 & 64.8 & & \\
\hline Supraglottic & 331 & 58.6 & 48.7 & & \\
\hline Subglottic & 44 & 72.7 & 56.2 & & \\
\hline Blood group & & & & 11.637 & 0.009 \\
\hline$A$ & 347 & 76.0 & 67.5 & & \\
\hline B & 332 & 69.8 & 58.4 & & \\
\hline$A B$ & 101 & 73.1 & 65.6 & & \\
\hline $\mathrm{O}$ & 480 & 66.4 & 55.5 & & \\
\hline T category & & & & 101.754 & $<0.001$ \\
\hline $\mathrm{T} 1$ & 434 & 84.2 & 72.0 & & \\
\hline $\mathrm{T} 2$ & 382 & 74.3 & 63.0 & & \\
\hline T3 & 244 & 59.4 & 51.4 & & \\
\hline $\mathrm{T} 4$ & 200 & 46.8 & 41.1 & & \\
\hline N category & & & & 119.722 & $<0.001$ \\
\hline NO & 1021 & 76.9 & 66.1 & & \\
\hline $\mathrm{N}+$ & 239 & 43.0 & 35.4 & & \\
\hline UICC stage & & & & 127.473 & $<0.001$ \\
\hline I & 421 & 85.4 & 73.5 & & \\
\hline$\|$ & 326 & 77.2 & 65.3 & & \\
\hline III & 242 & 62.4 & 52.6 & & \\
\hline IV & 271 & 46.3 & 41.4 & & \\
\hline
\end{tabular}

UICC Union for International Cancer Control

a Patients were divided into two groups according to the median age

b Smoking index was defined as the number of cigarettes smoked per day $\times$ the total smoking duration (years)

\section{Discussion}

In our study of 1260 patients with laryngeal cancer, we investigated the association between the $\mathrm{ABO}$ blood 
Table 3 Multivariate analysis of OS with the Cox proportional hazards model

\begin{tabular}{lllr}
\hline Variable & Hazard ratio & $\mathbf{9 5 \%} \mathrm{Cl}$ & \multicolumn{1}{c}{$\boldsymbol{P}$} \\
\hline Alcohol consumption & 1.218 & $1.009-1.470$ & 0.040 \\
Tumor differentiation & 1.201 & $1.057-1.365$ & 0.005 \\
Primary site & 0.889 & $0.738-1.071$ & 0.215 \\
T category & 1.334 & $1.213-1.468$ & $<0.001$ \\
ABO blood group & 1.101 & $1.023-1.184$ & 0.010 \\
Sex & 0.425 & $0.175-1.034$ & 0.059 \\
Age & 1.877 & $1.558-2.260$ & $<0.001$ \\
Smoking index & 1.122 & $0.934-1.349$ & 0.220 \\
N category & 2.203 & $1.749-2.774$ & $<0.001$ \\
\hline
\end{tabular}

$\mathrm{Cl}$ confidence interval

group and clinicopathologic characteristics and patient prognosis. We found no significant association between clinicopathologic characteristics and the $\mathrm{ABO}$ blood group. Univariate and multivariate analyses showed that the $\mathrm{ABO}$ blood group was significantly associated with the prognosis of patients with laryngeal cancer.

There are more than 100 recognized blood group systems composed of more than 500 antigens [7], of which the $\mathrm{ABO}$ blood group is considered the most important [8]. The ABO blood group is determined by the presence of A or B blood group antigens on the surface of red blood cells, which consist of proteins and carbohydrates attached to lipids or proteins. Red blood cell antigens have various functions, such as membrane structural integrity, transportation of molecules through membranes, and adhesion [9]. Along with their expression on red blood cells, ABO antigens are highly expressed on human tissues and most epithelial and endothelial cells $[10,11]$. Since the first report by Aird et al. [12] that showed an association between blood group $\mathrm{A}$ and gastric cancer, the relationship between the $\mathrm{ABO}$ blood group and the risk, incidence, and clinicopathologic characteristics of human tumors has been suspected. Moreover, many studies have suggested a possible relationship between $\mathrm{ABO}$ blood group antigens and progression of human tumors [13-18]. Several plausible mechanisms, such as inflammation, immune-surveillance of malignant cells, and membrane signaling, have been proposed to explain this observed association between the ABO blood group and cancer risk [19]. Whereas the relationship between the $\mathrm{ABO}$ blood group and the incidence of laryngeal cancer remains unclear [4-6], the association between the $\mathrm{ABO}$ blood group and the risk of pancreatic cancer has been reported for over 40 years. Compared with people with blood group $\mathrm{O}$, people with non-O blood groups have an adjusted hazard ratio (HR) for pancreatic cancer of 1.44 (95\% confidence interval
[CI] 1.14-1.82) [19]. Many studies have been conducted to examine the underlying mechanism of this relationship. For example, the multinational Pancreatic Cancer Cohort Consortium identified pancreatic cancer susceptibility loci in the ABO gene [20]. In this study, 1896 patients with pancreatic cancer and 1939 controls were genotyped, and a significant association was reported with rs505922, a single nucleotide polymorphism (SNP) that maps to the first intron of the $\mathrm{ABO}$ gene. The $\mathrm{ABO}$ SNP rs505922 is in strong linkage disequilibrium with $\mathrm{O} /$ non-O blood group alleles, indicating that people with non-O blood groups are at increased risk for developing pancreatic cancer $[19,21,22]$. In addition, two recent genome-wide association studies identified variants in ABO (rs505922), 1q32.1 (rs3790844), 13q22.1 (rs9543325), and 5p15.3 (rs401681) that were associated with a modestly increased risk of pancreatic cancer [23]. Two other studies suggested that the association between A blood group and increased risk of pancreatic cancer is due mainly to the $\mathrm{A} 1$ allele, thus indicating a direct connection between $\mathrm{ABO}$ glycosyltransferase activity and increased risk of this disease [24, 25]. Risch et al. [26] reported that the increased risk of pancreatic cancer among people with non-O blood groups was even higher if they were also seropositive for CagA-negative Helicobacter pylori (odds ratio: 2.78; 95\% CI 1.49-5.20). Recently, Hofmann et al. [27] reported that healthy controls displayed significantly higher isoagglutinin titers and higher rate of binding to $\mathrm{Tn}$ and $\mathrm{T}$ antigen compared with patients with pancreatic ductal adenocarcinoma. Because Hofmann et al. [27] did not find an association between isoagglutinin titers and clinical parameters (such as OS and tumor stage), they assumed that isoagglutinins are important during tumorigenesis but not during actual tumor growth.

Our study showed, by both univariate and multivariate analyses, that the $\mathrm{ABO}$ blood group was an independent prognostic factor for patients with laryngeal cancer. Compared with patients with other ABO blood groups, patients with blood group $\mathrm{O}$ had significantly shorter OS.

There are only a few comparable studies in laryngeal cancer or in other types of head and neck cancer. A study by Ouyang et al. [28] indicated that nasopharyngeal carcinoma (NPC) patients with blood group A had significantly lower OS rate (adjusted HR $=1.49[95 \%$ CI 1.03-2.17]) and distant metastasis-free survival rate $(\mathrm{HR}=1.68$ [95\% CI 1.13-2.51]) than patients with non-A blood groups $(\mathrm{B}, \mathrm{AB}$, and $\mathrm{O})$. In the subgroup analyses, they found that the increased risks associated with blood group A were restricted to men. Sheng et al. [17] conducted a case-control study and found that male NPC patients with blood group A had a significantly higher rate of distant metastasis than male patients with non-A 
blood groups $(6.8 \%$ vs. $3.5 \%, P=0.027)$, which directly supports the poorer prognosis of men with blood group A. A possible reason for the different results between laryngeal cancer and NPC is that NPC has a distinct epidemiology, etiology, and clinical manifestation compared with other head and neck cancers, including laryngeal cancer $[29,30]$.

Our findings are similar to those of previous studies in non-muscle invasive bladder urothelial carcinoma and locoregional esophageal squamous cell carcinoma (ESCC). Klatte et al. [31] found that non-muscle invasive bladder urothelial carcinoma patients with blood group $\mathrm{O}$ had higher recurrence and progression rates than patients with blood group A $(P=0.015$ and 0.031 , respectively) or blood group $\mathrm{B}(P=0.004$ and 0.075 , respectively). In a subgroup analysis of 321 patients with ESCC who had ever smoked, Sun et al. [32] found that patients with blood group $\mathrm{B} / \mathrm{O}$ had lower OS rate than patients with blood group $\mathrm{A} / \mathrm{AB}(P=0.024)$. For ESCC patients who had ever smoked, multivariate analysis showed an unfavorable and independent effect of blood group $\mathrm{B} / \mathrm{O}$ on survival $(P=0.011)$. Our findings, however, are not in line with the findings of previous studies on pancreatic cancer, renal cell carcinoma, and curatively resected non-small cell lung cancer (NSCLC). For example, Engin et al. [33] and Rahbari et al. [34] found that pancreatic cancer patients with blood group $\mathrm{O}$ had a significantly longer survival than patients with non-O blood groups, regardless of prognostic factors. Kaffenberger et al. [35] showed that, in patients with renal cell carcinoma who underwent nephrectomy or partial nephrectomy, non-O blood groups were significantly associated with decreased OS (HR $=1.68,95 \% \mathrm{CI}$ $1.18-2.39, P=0.004)$. Li et al. [36] showed that NSCLC patients with blood group $\mathrm{O}$ or $\mathrm{B}$ had significantly longer OS, disease-free survival, and local recurrence-free survival than NSCLC patients with blood group $A$ or $A B$.

The results of studies evaluating the prognostic value of the $\mathrm{ABO}$ blood group in various cancers are quite conflicting. There are several possible explanations for the heterogeneity of findings across the studies. First, many studies were performed without the understanding that $\mathrm{ABO}$ frequencies can vary widely in populations assumed to be ethnically homogeneous; therefore, they included a limited number of patients and inappropriate control groups. Second, many studies were retrospective. Third, many recent studies that determined the association between the $\mathrm{ABO}$ blood group and the occurrence of malignant neoplastic disease are still preliminary or controversial, frequently not supported by strong statistical data. Underlying mechanisms still need to be explored or confirmed.
In our study, the distribution of the $\mathrm{ABO}$ blood group was similar to that in the Zhejiang [17] and Guangdong populations [32], with blood group O having the highest percentage (38.1\%) and blood group $\mathrm{AB}$ having the lowest percentage $(8.0 \%)$. It is still unclear why $\mathrm{ABO}$ blood groups affect the survival of patients with laryngeal cancer. Since no significant differences in the basic characteristics of patients with different $\mathrm{ABO}$ blood groups were observed, it is difficult to explain the effect of the ABO blood group. However, underlying molecular and pathogenic differences may play important roles in the effect of the $A B O$ blood group on survival.

Our study had several limitations. First, it was conducted at a single center. Second, to detect an association between the ABO blood group and survival of patients with laryngeal cancer, we selected only the patients with locoregional disease that underwent curative treatment. Therefore, metastatic cases were excluded and not discussed. Third, despite the fact that the patients enrolled in this study mostly came from Guangdong province, some of them came from other areas in China. Fourth, worldwide, the general sex ratio (men:women) of laryngeal cancer is $8-10: 1$, but in our study, the ratio was 36.1:1. These limitations weaken the applicability of our data.

In conclusion, this study provides evidence of an association between the $\mathrm{ABO}$ blood group and survival of patients with laryngeal cancer: patients with blood group $\mathrm{O}$ had lower OS rate than patients with non-O blood groups. Further basic research on tumor genetic or biological differences associated with the ABO blood group is needed.

\section{Authors' contributions}

XZC and WHH conceived of the study and participated in its design and coordination. PJL performed the statistical analyses and interpretation. TJ drafted the manuscript. All authors read and approved the final manuscript.

\section{Author details}

${ }^{1}$ Key Laboratory of Radiation Oncology in Zhejiang Province, Hangzhou 310022, Zhejiang, P. R. China. ${ }^{2}$ Department of Radiation Oncology, Zhejiang Cancer Hospital, 38 Guang Ji Road, Hangzhou 310022, Zhejiang, P. R. China. ${ }^{3}$ State Key Laboratory of Oncology in South China, Department of Radiation Oncology, Collaborative Innovation Center of Cancer Medicine, Sun Yat-sen University Cancer Center, No. 651 Dongfeng Road East, Guangzhou 510060, Guangdong, P. R. China.

\section{Acknowledgements}

This study was supported by the grants from the National Natural Science Foundation of China (Grant No. 81372437), the China International Medical Foundation (No. CIMF-F-H001-043), and the Excellent Talents Project of Zhejiang Cancer Hospital, China (No. 2013 to T.J.).

\section{Competing interests}

The authors declare that they have no competing interests.

Received: 27 October 2015 Accepted: 27 September 2016

Published online: 13 October 2016 


\section{References}

1. Siegel R, Naishadham D, Jemal A. Cancer statistics, 2013. CA Cancer J Clin. 2013:63:11-30

2. Li X, Gao L, Li H, Gao J, Yang Y, Zhou F, et al. Human papillomavirus infection and laryngeal cancer risk: a systematic review and meta-analysis. J Infect Dis. 2013;207:479-88.

3. Adam SI, Wilson KM, Overholser SM, Khabbaz E, Moreno K, Patil YJ. Are laryngeal squamous cell carcinoma incidence and patient mortality a function of $\mathrm{ABO}$ blood grouping? A retrospective study. J Laryngol Otol. 2012;126:180-4

4. Konieczna A, Turowski G. ABO blood groups system in laryngeal cancer patients and after survival of 3 and 5 years. Mater Med Pol. 1992;24:266-7.

5. Pyd M, Rzewnicki I, Suwayach U. ABO blood groups in patients with laryngeal and hypopharyngeal cancer. Otolaryngology. 1995;49(20):396-8 (in Polish).

6. Nowinska E, Namyslowski G, Scierski W, Kocierz S. ABO blood groups in the patients with laryngeal cancer. Otolaryngology. 2000;54(31):209-11 (in Polish)

7. Dzieczkowski JS, Anderson KC. Blood group antigens and therapy. In: Harrison TR, Fauci AS, editors. Principles of international medicine. 14th ed. New York: McGraw-Hill; 1998. p. 718-9.

8. Franchini M, Favaloro EJ, Targher G, Lippi G. ABO blood group, hypercoagulability, and cardiovascular and cancer risk. Crit Rev Clin Lab Sci. 2012:49:137-49.

9. Reid ME, Mohandas N. Red blood cell blood group antigens: structure and function. Semin Hematol. 2004;41:93-117.

10. Strauchen JA, Bergman SM, Hanson TA. Expression of A and B tissue isoantigens in benign and malignant lesions of the breast. Cancer. 1980:45:2149-55

11. Schuessler MH, Pintado S, Welt S, Real FX, Xu M, Melamed MR, et al. Blood group and blood-group-related antigens in normal pancreas and pancreas cancer: enhanced expression of precursor type 1, Tn and sialyl-Tn in pancreas cancer. Int J Cancer. 1991:47:180-7.

12. Aird I, Bentall HH, Roberts JA. A relationship between cancer of stomach and the ABO blood groups. Br Med J. 1953:1:799-801.

13. Gong Y, Yang YS, Zhang XM, Su M, Wang J, Han JD, et al. ABO blood type, diabetes and risk of gastrointestinal cancer in northern China. World J Gastroenterol. 2012;18:563-9.

14. Gates MA, Xu M, Chen WY, Kraft P, Hankinson SE, Wolpin BM. ABO blood group and breast cancer incidence and survival. Int J Cancer. 2012;130:2129-37.

15. Xie J, Qureshi AA, Li Y, Han J. ABO blood group and incidence of skin cancer. PLoS One. 2010;5:e11972.

16. Wang DS, Chen DL, Ren C, Wang ZQ, Qiu MZ, Luo HY, et al. ABO blood group, hepatitis B viral infection and risk of pancreatic cancer. Int J Cancer. 2012;131:461-8.

17. Sheng L, Sun X, Zhang L, Su D. ABO blood group and nasopharyngeal carcinoma risk in a population of Southeast China. Int J Cancer. 2013;133:893-7.

18. Tavasolian F, Abdollahi E, Vakili M, Amini A. Relationship between ABO blood group and Acute Lymphoblastic Leukemia. Iran J Ped Hematol Oncol. 2014;4:1-4

19. Wolpin BM, Chan AT, Hartge P, Chanock SJ, Kraft P, Hunter DJ, et al $\mathrm{ABO}$ blood group and the risk of pancreatic cancer. J Natl Cancer Inst. 2009:101:424-31.

20. Amundadottir L, Kraft P, Stolzenberg-Solomon RZ, Fuchs CS, Petersen GM, Arslan AA, et al. Genome-wide association study identifies variants in the $\mathrm{ABO}$ locus associated with susceptibility to pancreatic cancer. Nat Genet. 2009:41:986-90.
21. Wolpin BM, Kraft P, Gross M, Helzlsouer K, Bueno-de-Mesquita HB, Steplowski E, et al. Pancreatic cancer risk and ABO blood group alleles: results from the pancreatic cancer cohort consortium. Cancer Res. 2010;70:1015-23.

22. Xu HL, Cheng JR, Zhang W, Wang J, Yu H, Ni QX, et al. Re-evaluation of $\mathrm{ABO}$ gene polymorphisms detected in a genome-wide association study and risk of pancreatic ductal adenocarcinoma in a Chinese population. Chin J Cancer. 2014;33:68-73

23. Klein AP, Lindstrom S, Mendelsohn JB, Steplowski E, Arslan AA, Buenode-Mesquita $\mathrm{HB}$, et al. An absolute risk model to identify individuals at elevated risk for pancreatic cancer in the general population. PLoS One. 2013;8:e72311.

24. Wolpin BM, Kraft P, Xu M, Steplowski E, Olsson ML, Arslan AA, et al. Variant ABO blood group alleles, secretor status, and risk of pancreatic cancer: results from the pancreatic cancer cohort consortium. Cancer Epidemiol Biomarkers Prev. 2010:19:3140-9.

25. Rizzato C, Campa D, Pezzilli R, Soucek P, Greenhalf W, Capurso G, et al. $A B O$ blood groups and pancreatic cancer risk and survival: results from the PANcreatic Disease ReseArch (PANDoRA) consortium. Oncol Rep. 2013:29:1637-44

26. Risch HA, Yu H, Lu L, Kidd MS. ABO blood group, Helicobacter pylori seropositivity, and risk of pancreatic cancer: a case-control study. J Natl Cancer Inst. 2010;102:502-5.

27. Hofmann BT, Stehr A, Dohrmann T, Gungor C, Herich L, Hiller J, et al. ABO blood group IgM isoagglutinins interact with tumor-associated O-glycan structures in pancreatic cancer. Clin Cancer Res. 2014;20:6117-26.

28. Ouyang PY, Su Z, Mao YP, Liu Q, Xie FY. Prognostic value of ABO blood group in southern Chinese patients with established nasopharyngeal carcinoma. Br J Cancer. 2013;109:2462-6.

29. Chang ET, Adami HO. The enigmatic epidemiology of nasopharyngeal carcinoma. Cancer Epidemiol Biomarkers Prev. 2006:15:1765-77.

30. Wei WI, Sham JS. Nasopharyngeal carcinoma. Lancet. 2005;365:2041-54.

31. Klatte T, Xylinas E, Rieken M, Kluth LA, Roupret M, Pycha A, et al. Impact of $\mathrm{ABO}$ blood type on outcomes in patients with primary nonmuscle invasive bladder cancer. J Urol. 2014;191:1238-43.

32. Sun P, Chen C, Zhang F, An X, Li XY, Li YH, et al. The ABO blood group predicts survival in esophageal squamous cell carcinoma in patients who ever smoked: a retrospective study from China. Tumour Biol. 2014;35:7201-8.

33. Engin $\mathrm{H}$, Bilir $\mathrm{C}$, Ustun $\mathrm{H}$, Gokmen $\mathrm{A}$. ABO blood group and risk of pancreatic cancer in a Turkish population in Western Blacksea region. Asian Pac J Cancer Prev. 2012;13:131-3.

34. Rahbari NN, Bork U, Hinz U, Leo A, Kirchberg J, Koch M, et al. ABO blood group and prognosis in patients with pancreatic cancer. BMC Cancer. 2012;12:319.

35. Kaffenberger SD, Morgan TM, Stratton KL, Boachie AM, Barocas DA, Chang SS, et al. ABO blood group is a predictor of survival in patients undergoing surgery for renal cell carcinoma. BJU Int. 2012;110:E641-6.

36. Li N, Xu M, Li CF, Ou W, Wang BX, Zhang SL, et al. Prognostic role of the $\mathrm{ABO}$ blood types in Chinese patients with curatively resected non-small cell lung cancer: a retrospective analysis of 1601 cases at a single cancer center. Chin J Cancer. 2015;34:54.

\section{Submit your next manuscript to BioMed Central and we will help you at every step:}

- We accept pre-submission inquiries

- Our selector tool helps you to find the most relevant journal

- We provide round the clock customer support

- Convenient online submission

- Thorough peer review

- Inclusion in PubMed and all major indexing services

- Maximum visibility for your research

Submit your manuscript at www.biomedcentral com/submit
Ciomed Central 